\title{
TNFRp55 deficiency promotes the development of ectopic endometriotic-like lesions in mice
}

\author{
Sandra Vallcaneras', Federica Ghersa', Juan Bastón², María Belén Delsouc', \\ Gabriela Meresman² and Marilina Casais ${ }^{1}$ \\ 'Laboratorio de Biología de la Reproducción (LABIR), Facultad de Química, Bioquímica y Farmacia, \\ Universidad Nacional de San Luis, Instituto Multidisciplinario de Investigaciones Biológicas de San Luis \\ (IMIBIO-SL-CONICET), San Luis, Argentina \\ 2Laboratorio de Fisiopatología Endometrial, Instituto de Biología y Medicina Experimental (IBYME-CONICET), \\ Buenos Aires, Argentina
}

Correspondence should be addressed to $\mathrm{M}$ Casais

Email

mcasais@unsl.du.ar

\begin{abstract}
Endometriosis is an inflammatory disease depending on estradiol, with TNF- $\alpha$ being one of the most representative cytokines involved in its pathogenesis. TNF- $\alpha$ acts through its bond to the TNFRp55 and TNFRp75 membrane receptors. The aim of this study was to analyze the effect of the TNFRp55 deficiency on the development of ectopic endometriotic-like lesions. Endometriosis was induced surgically in mice of the C57BL/6 strain, wild type (WT) and TNFRp55-I- (KO). After four weeks, the peritoneal fluid was collected and the lesions were counted, measured with a caliper, removed, weighed, fixed or kept at $-80^{\circ} \mathrm{C}$. We evaluated the cell proliferation by proliferating cell nuclear antigen (PCNA) immunohistochemistry and apoptosis by TUNEL technique in the ectopic lesions. MMP-2 and MMP-9 activities (factors involved in invasiveness) were measured by zymography in the peritoneal fluid; estradiol and progesterone levels were measured by radioimmunoassay in the lesions and in the peritoneal fluid. We found that in $\mathrm{KO}$ animals the mean number of lesions established per mouse, the lesion volume, weight and cell proliferation increased and apoptosis decreased. In addition, the activity of MMP-2 and the estradiol level increased, whereas the progesterone level was not significantly modified. In conclusion, the deficiency of TNFRp55 promoted the establishment and development of endometriosis through an increase in the lesion size and high levels of estradiol which correlate with an increase in the MMP-2 activity. This is evidence of the possible association of the deregulation of the TNFRp55 expression and the survival of the endometriotic tissue in ectopic sites.
\end{abstract}

Journal of Endocrinology (2017) 234, 269-278

\section{Introduction}

Endometriosis is a chronic disease, depending on estrogens, that affects women at reproductive age, causing inflammation, intense pelvic pain and reduced fertility. It is characterized by the implantation and growth of endometrial tissue outside the uterine cavity
(Greene et al. 2016). Sampson's theory, which states that epithelial and stromal cells reach the peritoneal cavity through late menstruation through the fallopian tubes and are then spread and implanted in the peritoneal cavity, is the mostly accepted mechanism to explain

Published by Bioscientifica Ltd. 
its etiology (Sampson 1927). However, this theory does not explain why more than $90 \%$ of women with late menstrual bleeding do not develop endometriosis, which suggests that there are genetic, immunological and/or biochemical factors that contribute to the development of the disease (Ahn et al. 2015). A significant component in the pathogenesis of endometriosis is the loss of normal patterns of communication between the endocrine and immune systems. It is known that endometrial cells reduce their capacity of death by apoptosis and increase their capacity of invasiveness associated to hormonal alterations. These changes promote the resistance of the endometrial cells to the normal cleaning of the peritoneum by the immune system, responsible for the regulation of tissue homeostasis (Kitawaki et al. 2002, Antsiferova \& Sotnikova 2012).

Tumor necrosis factor-alpha (TNF- $\alpha$ ), has an important function in the physiology of the proliferation and desquamation of the endometrium during the menstrual cycle. In addition, it plays a crucial role in inflammation, angiogenesis, cell proliferation and cell death. TNF- $\alpha$ acts on the target cells via two receptors: TNFRp55 (type 1) and TNFRp75 (type 2). TNFRp55 is characterized by a death domain in its intracellular region, whereas type 2 receptor lacks such domain. Thus, the activation of TNFRp55 leads primarily to pro-inflammatory and programmed cell death pathways (Rojas-Cartagena et al. 2005). In endometriosis, there is evidence that indicates an aberrant function of the TNF system. For example, levels of TNFRp55 expression in the endometrium of women with endometriosis during the late secretory phase, stage related to the apoptosis, were lower in relation to the endometrium without endometriosis, in coincidence with the almost absent apoptosis in the eutopic and ectopic endometrium (Boric et al. 2013). In addition, a recent study that examined the serum levels of the soluble forms of both TNFRp55 and TNFRp75, has found that TNFRp55 is significantly higher in the serum of endometriosis patients than in that of controls, and given that these soluble forms can modulate the effects of TNF by acting as antagonists (Othman et al. 2016), this may also be involved in the altered cell death observed in this pathology.

On the other hand, the metalloproteinases (MMPs) are essential factors in the processes of invasiveness and tissue remodeling, which are secreted as latent pro-enzymes and activated by proteolytic cleavage (Di Carlo et al. 2009). Gelatin is an important protein of the extracellular matrix and it is sensitive to a high range of tissue proteinases, including MMP-2 and MMP-9 gelatinases (Jana et al. 2016,
Pan et al. 2016). These enzymes participate in the physiological cyclic changes of the endometrium, and several studies have shown that their steroid regulation is critical for the formation of the fragments of the endometrial tissue in ectopic sites (Bruner et al. 1997, Pitsos \& Kanakas 2009). In relation to this, there exists a correlation between the levels of MMP-2 and estradiol in the peritoneal fluid of patients with endometriosis (Huang et al. 2004).

In turn, steroid hormones play an important role in the development of this pathology. Endometriosis seems to be associated to a decrease in the response capacity of the endometrial stromal cells to progesterone, which may be due to a decrease in the expression of the progesterone receptors (PR). A recent study demonstrates that inflammatory cytokines like TNF $\alpha$ reduce the expression of PR. Thus, this effect may contribute to the progesterone resistance of women with endometriosis, which in turn is associated with hyperactive action of estradiol (Bulun et al. 2006, Grandi et al. 2016, Li et al. 2016). The proinflammatory and antiapoptotic effects of estradiol in endometrial cells appear to be exacerbated in women with endometriosis (Reis et al. 2013).

In view of all the above, the aim of this study was to analyze the effect of the TNFRp55 deficiency on the establishment and growth of endometriotic-like lesions in an induced endometriosis model in mouse. In addition, we evaluated cell proliferation and apoptosis of endometriotic cells as well as factors related to invasiveness and endocrine status.

\section{Materials and methods}

\section{Animals}

Female mice of the C57BL/6 strain, WT and TNFRp55-/(KO) of two months, weighing 19-21g were used. The TNFRp55-/- mice were obtained from the Max von Pettenkofer-Institute, Munich, Germany. Breeding colonies were established at the Animal Facility of the National University of San Luis (San Luis, Argentina) under rigorous light conditions (12h light, 07:00-19:00, and $12 \mathrm{~h}$ darkness), controlled temperature $\left(22 \pm 2^{\circ} \mathrm{C}\right)$, with water and sterile food ad libitum. The experiments were carried out according to the guidelines for the care and use of laboratory animals of the National Institutes of Health (NIH) and the Comité Institucional de Cuidado y Uso de Animales de Experimentación (CICUA) of the National University of San Luis, Argentina. 


\section{Surgical induction of endometriosis}

The endometriotic-like lesions were induced experimentally, as reported previously (Bilotas et al. 2010). The animals were anesthetized via intraperitoneal with $100 \mathrm{mg} / \mathrm{kg}$ of ketamine (Holliday Scott, Buenos Aires, Argentina) and $10 \mathrm{mg} / \mathrm{kg}$ of xylazine (Richmond, Buenos Aires, Argentina), and a mid-ventral incision was made to expose the bowels. The right uterine horn is removed from the animal, placed in DMEM-F12 (Gibco) and divided longitudinally. It is later cut in three square pieces of approximately $4 \mathrm{~mm}^{2}$, which are sutured to the intestine mesentery with only one stitch (supralong 6-0, Ethicon, NJ, USA). The area is hydrated with sterile physiological solution supplemented with antibiotic-antimycotic before closing the abdominal wall with the same suture material, with continuous stitches. The mice are monitored daily in relation to body weight, food consumption, preening behavior and activity. The mice were killed by cervix dislocation after four weeks. Then, a small medioventral hole was opened through which $1.5 \mathrm{~mL}$ of PBS was injected in the peritoneal cavity of each animal, and the peritoneal fluid was collected and centrifuged at $10,000 \boldsymbol{g}$ for $1 \mathrm{~min}$. The supernatant was separated from the precipitate and kept at $-80^{\circ} \mathrm{C}$ until the corresponding determinations. After that, the abdomen was completely opened to have access to the endometriotic-like lesions.

\section{Evaluation of the ectopic uterine tissue}

The lesions were identified, counted and measured with caliper in two perpendicular diameters. The volume of the developed lesions was calculated with the following equation: $V=(4 / 3) \pi r_{1}^{2} r_{2}\left(r_{1}\right.$ and $r_{2}$ are the radiuses and $r_{1}<r_{2}$ ). The lesions were removed, weighed and kept in as follows: one lesion per animal was fixed in buffer formaldehyde at $4 \%$ for $24 \mathrm{~h}$ at $4^{\circ} \mathrm{C}$. The fixed specimens are embedded in paraffin, cut in $5 \mu \mathrm{m}$ sections and stained with hematoxylin-eosin in order to examine microscopically the presence of histological identity signals of endometriosis (glands and stroma), or prepared for immunohistochemical technique and/or TUNEL. The remaining lesions were kept at $-80^{\circ} \mathrm{C}$ for the rest of the determinations.

\section{Immunohistochemistry}

Proliferating cell nuclear antigen (PCNA), also called cyclin, is a $36-\mathrm{KD}$ auxiliary protein of DNA polymerase delta that has been found to be a useful marker in immunocytochemical studies of cell proliferation because its expression correlates with the proliferative state of the cell (Bravo et al. 1987). All sections were deparaffinized in xylene and rehydrated through graded alcohols. Endogenous peroxidase was blocked by treatment with $3 \% \mathrm{H}_{2} \mathrm{O}_{2}$ for $30 \mathrm{~min}$, followed by microwaving in $0.01 \mathrm{M}$ sodium citrate buffer for antigen retrieval. All the sections were then blocked with 4\% BSA in PBS for $2 \mathrm{~h}$ at room temperature and incubated overnight at $4^{\circ} \mathrm{C}$ with the anti-mouse PCNA rabbit polyclonal antibody (1:200, FL-261, Santa Cruz Biotechnology) in PBS with $1 \%$ BSA at room temperature. After that, sections were incubated for $1 \mathrm{~h}$ at room temperature with 1:200 goat biotinylated anti-rabbit IgG antibody (Sigma-Aldrich) followed by incubation with a streptavidin-peroxidise conjugate (VectorLabs, Burlingame, CA, USA) for $30 \mathrm{~min}$ at room temperature. The signal was developed with diaminobenzidine (DAB) as substrate (Cell Marque, CA, USA), and finally, the sections were counterstaining with Gill's hematoxylin, dehydrated through grades alcohols, clarified in xylene and properly mounted. As a negative control, one section of each slide was assayed without the primary antibody. PCNA-positive cells were identified by the presence of brown nuclear reactivity. The percentage of PCNA-positive cells was established using a standard light microscope at $400 \times$. Cell proliferation was quantified by counting a minimum of 100-150 randomly selected epithelial and stromal cells per field and independently of the number of cells, 4-6 random fields per section were counted. The percentage of proliferating cells was calculated on the total, and these percentages were then used to obtain the mean of each experimental group.

\section{TUNEL assay}

Fragmented DNA of apoptotic cells was detected using In Situ Cell Death Detection Kit POD TUNEL assay (Cat No. 11684817910 Roche), according to the manufacturer's instructions. The detection was achieved using the peroxidase substrate, hydrogen peroxide and the stable chromogen DAB. Using this procedure, apoptotic nuclei are stained dark brown. Finally, sections were counterstained with hematoxylin, mounted and analyzed in a light microscope. The number of apoptotic nuclei relative to total cells was determined by counting 150 randomly selected epithelial and stromal cells per field, and 5 random fields per section were counted. The percentage of apoptotic cells was calculated on the total, and these percentages were then used to obtain the mean of each experimental group.

Published by Bioscientifica Ltd 


\section{Gelatin zymography}

MMP-2 and MMP-9 enzymatic activities were determined bySDS-PAGE gelatin zymography. The samples, normalized in the same quantity of proteins, were mixed with the same volume of the sample buffer $(0.3 \mathrm{M}$ Tris- $\mathrm{HCl} \mathrm{pH} 6.8$, $2 \%$ SDS, $40 \%$ glycerol and $0.1 \%$ bromophenol blue) and incubated for approximately $30 \mathrm{~min}$ at $37^{\circ} \mathrm{C}$. Then they were subjected to electrophoresis in polyacrylamide gels at $10 \%$ (SDS-PAGE) containing $0.2 \%$ of gelatin (Merck), under non-reducing denaturalizing conditions at $4^{\circ} \mathrm{C}$. Once electrophoresis was completed, the gels were washed with $2.5 \%$ of TritonX-100 (v/v) in buffer TNC ( $50 \mathrm{mM}$ Tris$\mathrm{HCl} \mathrm{pH} 7.5,0.5 \mathrm{M} \mathrm{NaCl}, 10 \mathrm{mM} \mathrm{CaCl}_{2}$ and $0.02 \% \mathrm{NaN}_{3}$ ), twice for $15 \mathrm{~min}$ to remove the SDS and thus allow the proteinases to recover their activity. After washing, the gels were incubated in TNC buffer with 1\% TritónX-100 for $24 \mathrm{~h}$ at $37^{\circ} \mathrm{C}$. Finally, the coloration with a $0.5 \%$ of Coomassie brilliant blue R-250 solution was carried out, with the subsequent discoloration. The MMPs activity was evaluated observing the lysis zones. The bands intensity was determined by densitometry using ImageJ software and was expressed in arbitrary units.

\section{Radioimmunoassay (RIA)}

Samples of peritoneal fluid supernatant and homogenates of endometriotic lesions were used to measure progesterone and estradiol levels using a RIA kit (Beckman Coulter and DIAsource, respectively, Diagnos Med SRL, Buenos Aires, Argentina) following the manufacturer's instructions. The assays sensitivity was $0.05 \mathrm{ng}$ progesterone $/ \mathrm{mL}$ and $<2.7 \mathrm{pg}$ estradiol $/ \mathrm{ml}$. The inter- and intra-assay coefficients of variation in all the assays were $<10.0 \%$.

\section{Western blot}

Protein extracts were obtained using TRIzol reagent, following the manufacturer's indications (Invitrogen Life Technologies). Protein concentration was determined by Lowry method. Aliquots containing $40 \mu \mathrm{g}$ of total protein were subjected to electrophoresis in 10\% SDS-PAGE gels and then electrotransferred to PVDF membrane (Millipore Corporation) at $100 \mathrm{~V}$ for $1 \mathrm{~h}$ in a transfer buffer $(25 \mathrm{mM}$ Tris, $192 \mathrm{mM}$ glycine and 20\%v/v methanol, $\mathrm{pH}$ 8.3). The membrane was immersed in 5\% non-fat milk in a PBST solution $\left(\mathrm{KH}_{2} \mathrm{PO}_{4} 0.015 \mathrm{M}, \mathrm{NaH}_{2} \mathrm{PO}_{4} 0.017 \mathrm{M}, \mathrm{KCl} 0.076 \mathrm{M}\right.$, $\mathrm{NaCl} 0.14 \mathrm{M}(\mathrm{pH} 7.4), 0.5 \%$ Tween 20 ) for $1 \mathrm{~h}$ at room temperature, followed by an overnight incubation at $4^{\circ} \mathrm{C}$ with either rabbit anti-P450aromatase (SC-30086) or goat anti ACTB (SC-1615, Santa Cruz Biotechnology), 1:1000 dilution in 1\% solution of non-fat powdered milk in PBST. After incubation with primary antibody, membranes were washed in PBST and incubated with donkey antigoat IgG peroxidase-linked antibody (Cat sc-2020, Santa Cruz Biotechnology) 1:5000 dilution in 1\% milk for $1 \mathrm{~h}$ at room temperature and goat anti-rabbit IgG peroxidaselinked antibody (Cat: sc-2004, Santa Cruz Biotechnology) 1:5000 dilution in $1 \%$ milk for $3 \mathrm{~h}$ at room temperature, respectively. Following washing in PBST, blots were developed using an enhanced chemiluminescence Western blotting detection system, Thermo Scientific SuperSignal West Pico Chemiluminescent (Pierce Biotechnology) and exposed to X-ray films, Thermo Scientific CL-XPosure Film (Pierce Biotechnology). The mean of intensity of each band was measured using the NIH ImageJ software (Image Processing and Analysis in Java fromhttp://rsb.info.nih. gov/ij/). P450aromatase (P450AROM) protein levels were normalized against ACTB (endogenous control).

\section{RNA isolation and RT-PCR analysis}

Total RNA was isolated from endometriotic lesions using TRIzol reagent (Invitrogen Life Technologies), according to the manufacturer's instructions. Purified total RNAs were then quantified and assessed for purity by measurement of the 260/280 ratio using an UV spectrophotometer Beckman DU-640 B (CA, USA). Only samples with $260 / 280$ ratio of $1.8-2.0$ were used. The integrity was confirmed by running $2 \mu \mathrm{g}$ RNA on a $0.8 \%$ agarose gel. After GelRed (Biotium, Hayward, CA, USA) staining, RNA bands were visualized with a UV transilluminator, and $28 \mathrm{~S}$ and $18 \mathrm{~S}$ rRNA band patterns were analyzed. Two micrograms of total RNA were reverse transcribed at $37^{\circ} \mathrm{C}$ using random primers and M-MLV Reverse Transcriptase (Promega) in a $26 \mu \mathrm{L}$ reaction mixture. For amplification of the reverse transcription (RT) products, the reaction mixture consisted of $1 \times$ Green GoTaq reaction buffer, $0.2 \mathrm{mM}$ deoxynucleoside triphosphates, $0.5 \mu \mathrm{M}$ specific oligonucleotide primers and $1.25 \mathrm{U}$ Go Taq DNA polymerase (Promega) in a final volume of $50 \mu \mathrm{L}$. The PCR primers were designed using Primer Express 3.0 software (Applied Biosystems). The primers information is shown in Table 1 . The cDNA was amplified using a thermal cycler (My Cycler, BioRad). Reaction products were electrophoresed on $2 \%$ agarose gels, visualized with GelRed and examined by ultraviolet transillumination. Band intensities of RT-PCR products were quantified using Image (Image Processing and Analysis in Java from 
http://rsb.info.nih.gov/ij/). Relative levels of mRNA were expressed as the ratio of signal intensity for the target genes relative to that for the housekeeping gene Actb.

\section{Statistical analysis}

Statistical analysis was performed using GraphPad Prism (Version 5, GraphPad Software). Values are presented as the mean \pm S.E.M. Differences between the means of each group were analyzed using the Student's $t$-test. Pearson's correlation coefficient was used to evaluate the relationship between estradiol levels and MMP-2 activity in peritoneal fluid. Differences were considered to be statistically significant when $P<0.05$.

\section{Results}

\section{Effect of the TNFRp55 deficiency on the endometriotic- like lesions establishment and growth}

The macroscopic evaluation of the ectopic uterine tissue revealed that the number of established lesions increased in animals with receptor deficiency $(P<0.05)$ (Fig. 1A). In addition, we observed that the lesions volume and weight were higher in $\mathrm{KO}$ animals than in WT animals $(P<0.05$ and $P<0.001$, respectively) (Fig. $1 \mathrm{~B}$ and C). These results show the relevance of TNFRp55 in the development of the ectopic endometrial tissue.

\section{Effect of the TNFRp55 deficiency on the cell proliferation} and apoptosis in endometriotic-like lesions

The TNFRp55 deficiency caused an increase in the percentage of cell proliferation $(P<0.01)$ (Fig. $2 \mathrm{~A})$ and a decrease in the percentage of apoptosis cells $(P<0.001)$ (Fig. 2B). There were no significant differences between

Table 1 Primer used for semi-quantitative RT-PCR amplification.

\begin{tabular}{|c|c|}
\hline Gen & Sequences (sense above, antisense below; $5^{\prime}-3^{\prime}$ ) \\
\hline \multirow[t]{2}{*}{$H s d 3 b 1$} & GTCTTCAGACCAGAAACCAAG \\
\hline & CCTTAAGGCACAAGTATGCAG \\
\hline \multirow[t]{2}{*}{ Akr1c18 } & TTCGAGCAGAACTCATGGCTA \\
\hline & CAACCAGGTAGAATGCCATCT \\
\hline \multirow[t]{2}{*}{$\operatorname{Pgr} A B$} & CTGTGCCTTACCATGTGGCA \\
\hline & TTCACCATGCCCGCCAGGAT \\
\hline \multirow[t]{2}{*}{ Pgr $B$} & GGTCCCCCTTGCTTGCA \\
\hline & CAGGACCGAGGAAAAAGCAG \\
\hline \multirow[t]{2}{*}{ P450arom } & CCCGAGCCTTTGGAGAACAA \\
\hline & TGAGGGTCAACACATCCACG \\
\hline \multirow[t]{2}{*}{ Actb } & CGGAACCGCTCATTGCC \\
\hline & ACCCACACTGTGCCCATCTA \\
\hline
\end{tabular}

epithelial and stromal cell. These results suggest that the increase in the volume and weight of the lesions in the $\mathrm{KO}$ animals might be associated to the low elimination rate and high proliferation rate of the endometriotic cells.

\section{Effect of TNFRp55 deficiency on the factors regulating invasiveness}

We analyzed the enzymatic activity of MMP-2 and MMP-9 in homogenates of endometriotic lesions and peritoneal fluid, and although no significant changes were observed in the lesion in both experimental groups (Fig. 3A), in peritoneal fluid, the activity of MMP-2 $(P<0.001)$ and its zymogene increased significantly in the $\mathrm{KO}$ animals $(P<0.01)$ (Fig. 3B). These results suggest that the TNFRp55 deficiency modifies the peritoneal environment, which contributes to the remodeling and establishment of lesions.

\section{Effect of the TNFRp55 deficiency on the steroid hormones levels}

In the $\mathrm{KO}$ animals, the levels of estradiol increased in the peritoneal fluid and in lesion $(P<0.05)$ (Fig. $4 \mathrm{~A}$ and $\mathrm{B}$ ), whereas the expression, analyzed in ectopic uterine tissue, (mRNA and protein) of P450arom, synthesis enzyme, was not significantly modified (Fig. 4C and D). These results indicate the close relationship between estradiol and TNFRp55. Pearson's test was applied to determine the possible correlation between estradiol levels and MMP-2 activity in peritoneal fluid samples. For the entire group of mice $(n=16)$, positive correlation was found (coefficient $(r)$ Pearson: $0.67 ; P<0.01$ ). While, there was no correlation in the wild-type mice $(n=8)$ and deficient mice $(n=8)$ (Fig. 5).

\begin{tabular}{|c|c|c|}
\hline GenBank accession \# & Amplicon length $(\mathrm{pb})$ & No. of cycles \\
\hline M58567 & 213 & 35 \\
\hline NM_134066 & 141 & 35 \\
\hline NM_008829.2 & 389 & 35 \\
\hline NM_008829 & 121 & 35 \\
\hline NM_007810.3 & 161 & 40 \\
\hline NM_007393.5 & 289 & 35 \\
\hline
\end{tabular}

Published by Bioscientifica Ltd. 
A

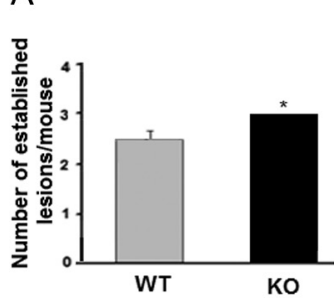

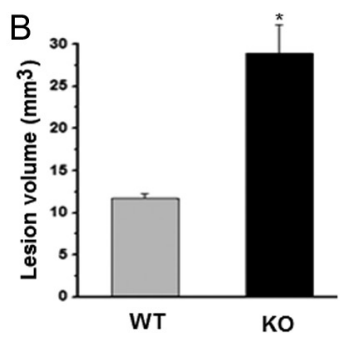

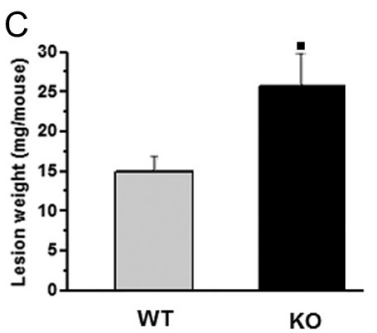

\section{Figure 1}

Establishment and growth of endometriotic lesions. The number of established endometriotic lesions (A), volume (B) and weight (C) were assessed in mice wild type (WT) $n=12$ year TNFRp55-/- (KO) $n=11$ after 4 week of induced endometriosis. Statistical comparisons were performed by Student's $t$-test. ${ }^{*} P<0.05$, $\square<0.001$
We also analyzed the effect of TNFRp55 deficiency on the progesterone levels in peritoneal fluid and homogenates of endometriotic lesions, the expression of the metabolic enzymes and PR. In KO animals, the levels of progesterone were not significantly modified (Fig. 6A and B), whereas the expression (mRNA) of $H s d 3 b 1$, synthesis enzyme, and of Akr1c18, degradation enzyme, decreased in endometriotic tissue $(P<0.01$ and $P<0.005$, respectively) (Fig. 6C); therefore, the hormone levels were not modified. To determine if the TNFRp55 deficiency modifies the action sites of progesterone, we analyzed the expression (mRNA) of the progesterone receptors $P g r A$ and $P g r B$, but no changes were observed (Fig. 6D)

\section{Discussion}

Extensive cell proliferation, tissue remodeling and aberrant apoptosis occur at the ectopic sites where endometrial tissue deposits develop into endometriotic lesions. In addition, there is evidence of an aberrant function of the TNF system in this pathology. In the endometrium of control women, the highest levels of TNF and TNFRp55 are produced during the late secretory phase. This phase is related to the apoptosis, which is the physiological process involved in the menstrual shedding in a non-conceptional cycle. In contrast, the levels of TNFRp55 expression in the endometrium of women with endometriosis during the late secretory phase are lower in relation to the endometrium
A

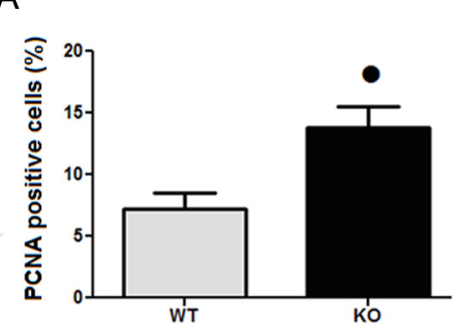

$\mathrm{B}$

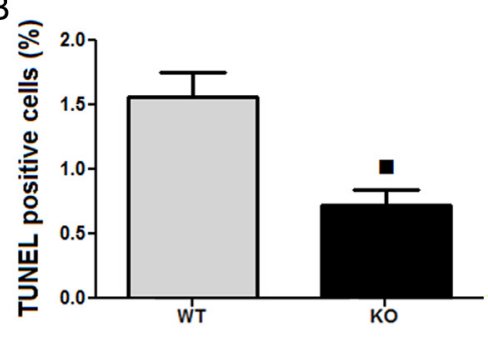

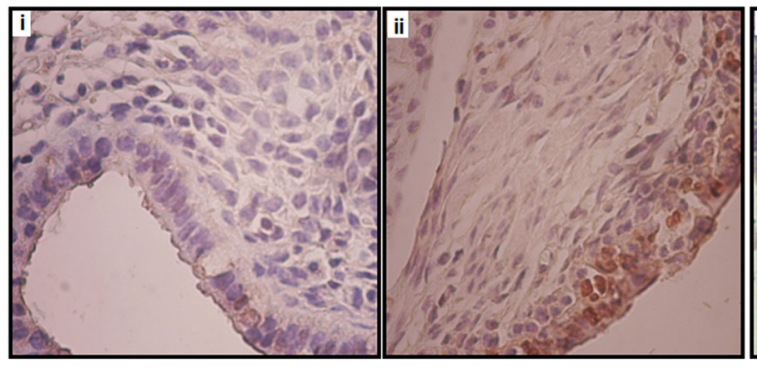

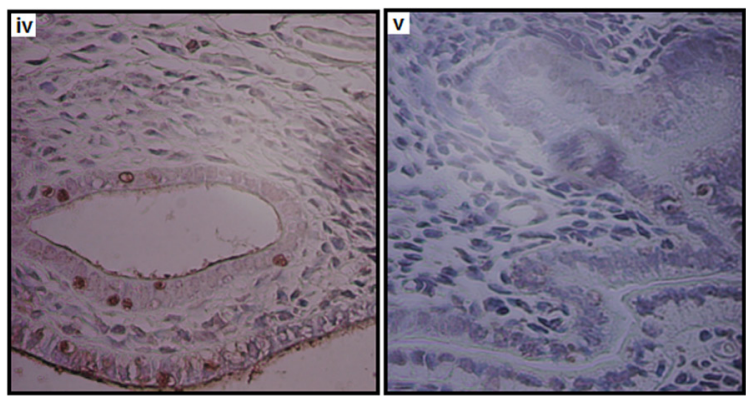

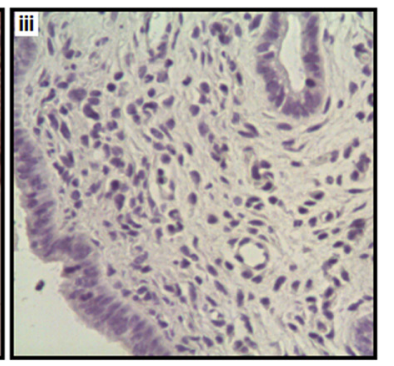

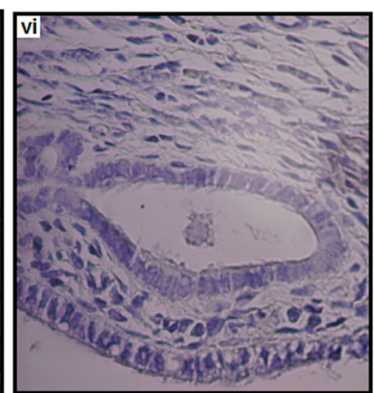

Figure 2

Cell proliferation and apoptosis in endometriotic lesions. (A) The percentage of proliferating cells was assessed by immunohistochemistry for PCNA in endometriotic lesions. Micrographs show representative histological sections of endometriotic lesions of WT $(n=11)$ (i) and KO $(n=7)$ (ii). As a negative control, one section of each slide was assayed without the primary antibody (iii). Statistical comparisons were performed by Student's $t$-test. $\bullet P<0.01$. (B) The percentage of apoptosis cells was assessed by TUNEL in endometriotic lesions. Micrographs show representative histological sections of endometriotic lesions of WT $(n=8)$ (iv) and KO $(n=8)(v)$. As a negative control, one section of each slide was assayed without the primary antibody (vi). Statistical comparisons were performed by Student's $t$-test. $\square P<0.001$. http://joe.endocrinology-journals.org DOI: 10.1530/JOE-17-0236
๑ 2017 Society for Endocrinology Printed in Great Britain
Published by Bioscientifica Ltd 
A
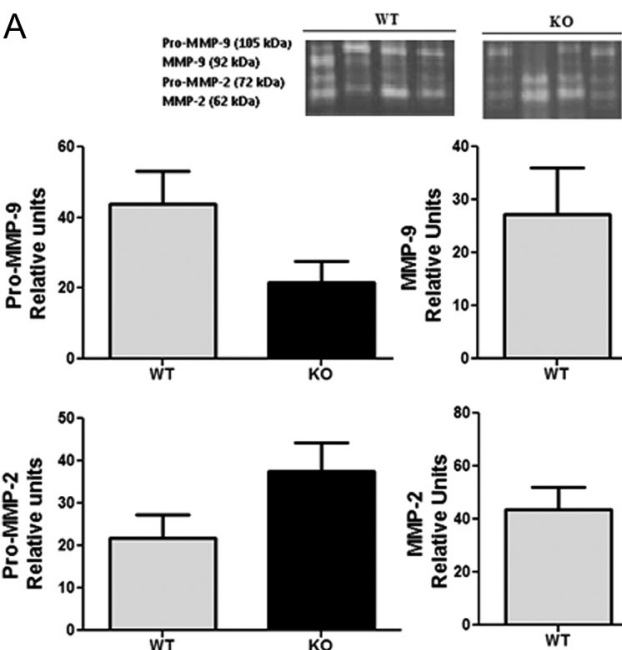

B
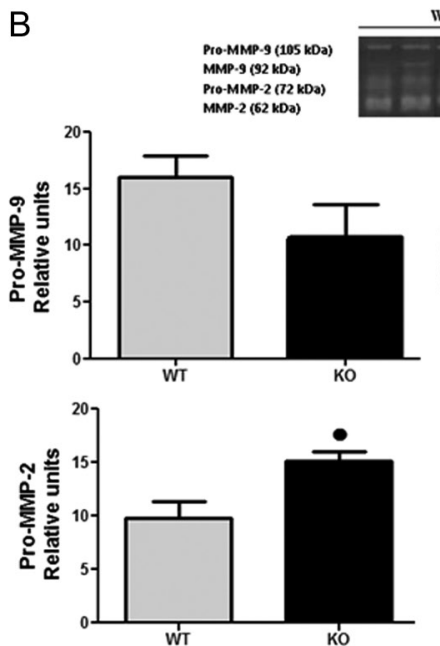
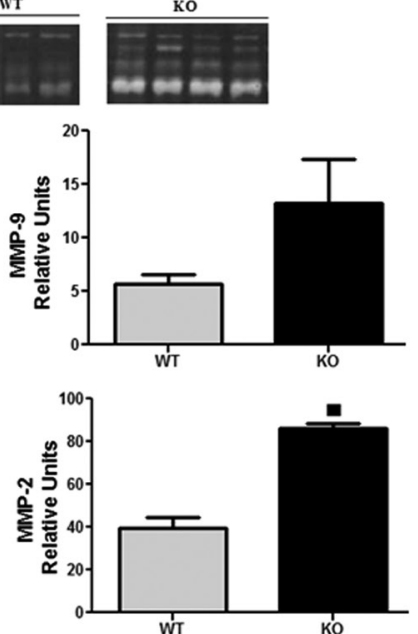

Figure 3

Enzyme activities of MMP-2 and MMP-9. MMP-2 and MMP-9 (proenzyme and active forms) enzymatic activities were determined by SDS-PAGE gelatin zymography in endometriotic lesions $(A)$ and peritoneal fluid $(B)$. The gel photographs were quantified using Image and expressed as in relative units. Results are expressed as mean \pm S.E.M. of eight animals per experimental group. Student's $t$-test was used. $\bullet P<0.01, \pm P<0.001$.

of women without endometriosis. This is in coincidence with the almost absent apoptosis in the eutopic and ectopic endometrium, which might favor the survival and growth of the menstrual debris outside the uterus (RojasCartagena et al. 2005, Boric et al. 2013). Considering that the abnormal survival of endometrial cells may result in their continuing growth into ectopic locations and that TNFRp55 plays a role in triggering apoptosis, in this study, we selected TNFRp55 as molecular target and we investigated the effect of TNFRp55 deficiency on the development of endometriotic-like lesion in a murine model. One of the major limitations of mouse model is the lack of menstruation and subsequent spontaneous endometriosis. However, this model has many similarities to the disease in humans, such as the growth of the ectopic endometrial tissue that has been shown to be estrogen dependent. In addition, it is a versatile model that has been used to investigate the mechanisms involved in the peritoneal attachment of endometrial cells, how the immune system and hormones affect endometriosis as well as the effects of drugs and therapeutic products (Grümmer 2006).
A
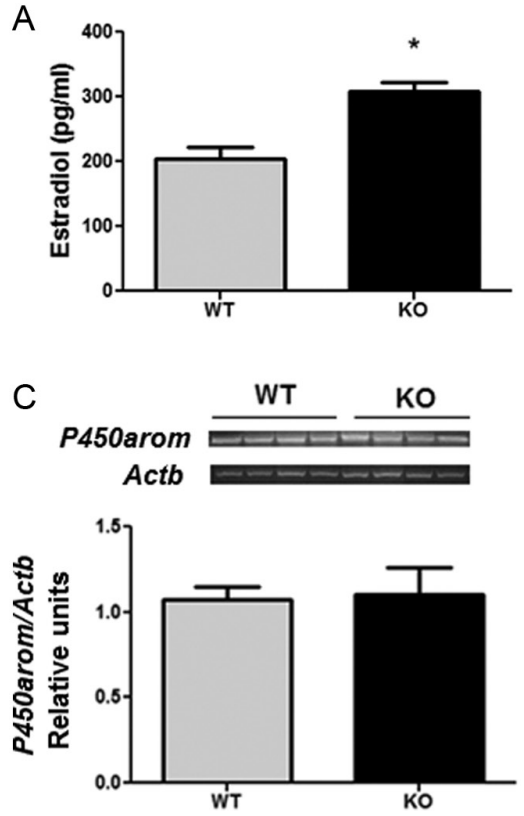
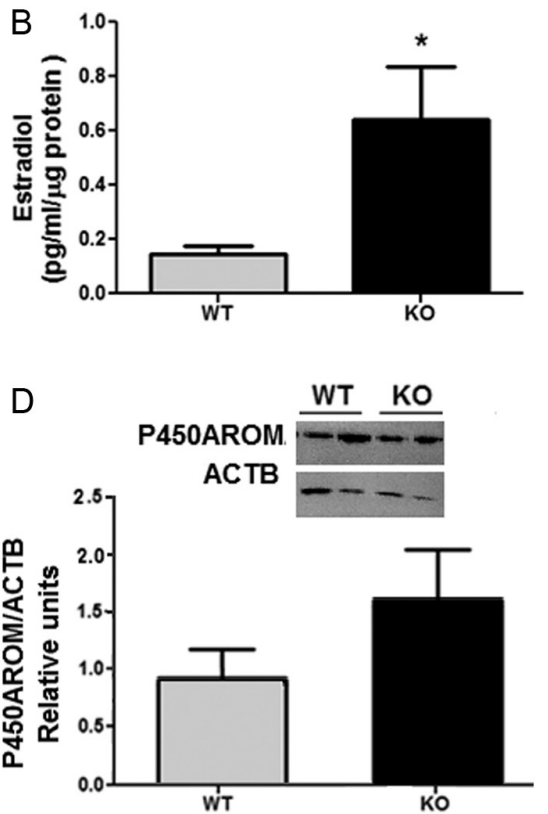

Figure 4

Estradiol levels and P450aromatase expression. Estradiol levels were measured by RIA in peritoneal fluid (A) and endometriotic lesions (B). Measurement by RT-PCR of expression (mRNA) of P450arom and Actb as housekeeping gene (C). Measurement by Western blot of expression (protein) of P450arom and Actb as load control (D). The gel photographs were quantified using ImageJ and expressed in relative units. Results are expressed as mean \pm S.E.M. of eight animals per experimental group. Student's $t$-test was used. $\star P<0.05$. 


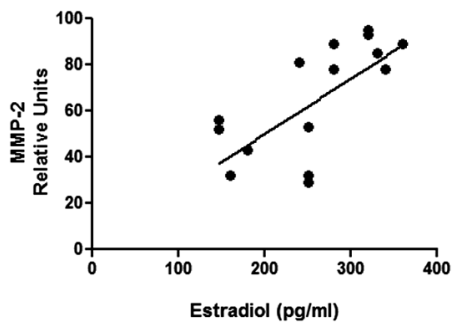

Figure 5

Pearson's correlation between estradiol levels and MMP-2 activity in peritoneal fluid samples. For the entire group of mice $(n=16)$, coefficient (r) Pearson: 0.67.

The obtained results show that the TNFRp55 deficiency promoted the establishment and the growth of endometriotic lesions associated to a high rate of cell proliferation and a low rate of apoptosis. Altogether, these data constitute strong evidence of the association of the deregulation of the TNFRp55 expression and the survival of the endometriotic tissue in ectopic sites.

The MMPs have a key role in the pathogenesis of endometriosis. Thus, in a model of induced endometriosis in mouse, it has been demonstrated that the activity suppression of these enzymes leads to inhibition in the endometriosis progression with the subsequent decrease in the weight of the endometriotic-like lesions (Bruner et al. 1997). In addition, increased levels of MMP-2 and MMP-9 have been detected in peritoneal fluid of patients with endometriosis (Amălinei et al. 2010). In our study, we detected an increase of the enzymatic activity of MMP-2 in the peritoneal fluid of the $\mathrm{KO}$ mice, which indicates that the TNFRp55 deficiency modifies the peritoneal environment contributing to the lesions remodeling and establishment. In turn, several studies have shown that the steroid regulation of MMP is critical for the formation of the fragments of the endometrial tissue in ectopic sites. In relation to this, there exists a correlation between the levels of MMP-2 and estradiol in the peritoneal fluid of patients with endometriosis (Huang et al. 2004). In agreement with this, we also observed the presence of high levels of estradiol that correlate with an increase in MMP-2 activity, which might favor the establishment and development of endometriotic lesions. It is important to emphasize that the TNFRp55-/- mice lack expression of TNFRp55 but display normal numbers of high affinity TNFRp75 molecules (Pfeffer et al. 1993). In surgically induced endometriosis in rat and mouse, the treatment with etanercept, a fusion protein consisting of human recombinant soluble TNFRp75 conjugated to a human Fc antibody subunit, was associated with negative immunohistochemical staining for TNFRp75 and reduced endometriosis development (Islimye et al. 2011, Liu et al. 2016). These data indicate that the lack of activity of the TNFRp75, a receptor associated mainly with proliferation, cell survival and angiogenesis (Haider et al. 2009, CabalHierro \& Lazo 2012), suppresses the development of endometriosis and that the effects observed in TNFRp55 deficient animals of the present study may be due to activation of TNFRp75-dependent pathways.

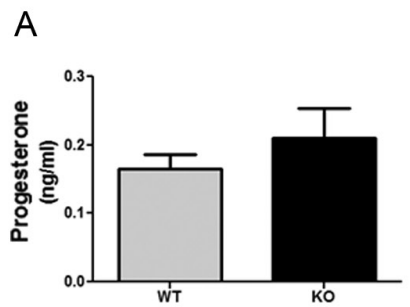

B

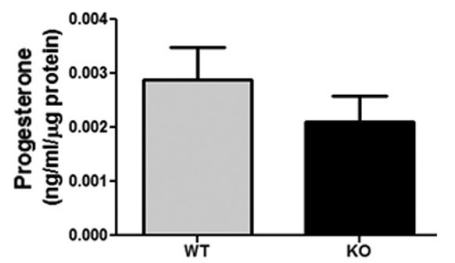

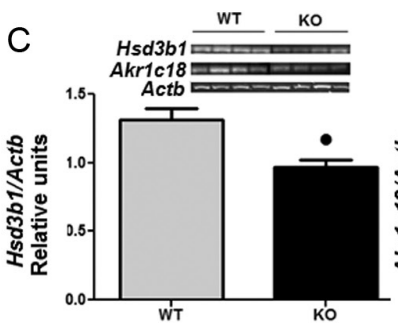

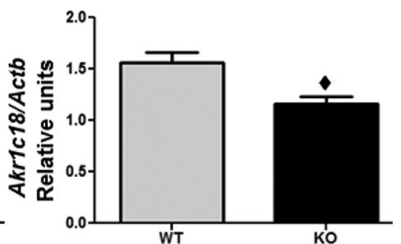

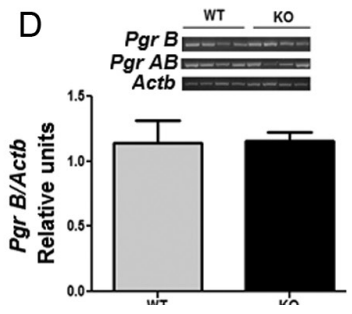
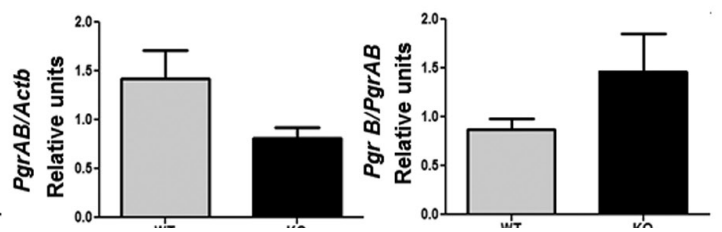

Figure 6

Progesterone levels, expression of metabolic enzymes and progesterone receptors. Progesterone levels were measured by RIA in peritoneal fluid (A) and endometriotic lesions (B) Measurement by RT-PCR of expression (mRNA) of Hsd3b1, Akr1c18 (C), Pgr (D). Actb was used as housekeeping gene. The gel photographs were quantified using ImageJ and expressed in relative units. Results are expressed as mean \pm S.E.M. of eight animals per experimental group. Student's $t$-test was used. $\bullet P<0.01, \bullet P<0.005$. 
Specifically in relation to the steroid hormones and endometriosis, estradiol is a factor favoring its development, while the role of progesterone seems to be attenuating. The TNFRp55 deficiency did not modify either the levels of progesterone or its action sites. On the other hand, we observed that the TNFRp55 deficiency caused a strong effect on the estradiol levels, which suggests the close relationship between estradiol and TNFRp55. It is well known that endometriotic lesions have the capacity to produce estradiol since they express the complete set of steroidogenic enzymes (Kianpour et al. 2015). Among these enzymes, P450arom plays an important role in endometriosis (Bulun et al. 2000, Bilotas et al. 2010). However, in our experimental model, this enzyme was not modified by the TNFRp55 deficiency. It is also important to take into account that the beginning and development of this disorder might be promoted not only by the estrogen synthesized at local level but also by the systemic estrogen (Rizner 2009). Thus, the estradiol from the ovary and from the conversion of androstenedione circulating in the adipose tissue and skin reaches the lesion via circulation. Therefore, the previous mechanism might explain the increase observed in the estradiol level in peritoneal fluid and endometriotic lesion.

There is strong evidence of the bidirectional communication between the endocrine and immune system. For example, it has been described that estrogens may contribute to tumor development, blocking the ability of immune cells to induce apoptosis of target cancer cells (Jiang et al. 2008). In endometriosis, the high level of estradiol can also play an important role in a local decrease of immunosurveillance (Vetvicka et al. 2016). In addition, in vitro studies suggest that endometriotic cells respond to estrogen-induced antiapoptotic signaling more intensely than normal cells (Reis et al. 2013). We postulate that hormones, especially estradiol, may regulate the expression of the gene that codifies TNFRp55 and that this might be a mechanism involved in the survival of the endometriotic cells in ectopic sites. In support of this hypothesis, we have mapped $1800 \mathrm{bp}$ upstream from the initial site of the Tnfrsfla gene transcription using MatInspector software (Quandt et al. 1995), and we identified four putative estrogen response elements and one putative progesterone response element (results not shown). In addition, a study through in situ hybridization demonstrated that the uterus of adult mice expresses mRNA of TNFRp55 and after the ovariectomy and $72 \mathrm{~h}$ of estradiol administration, the mRNA that codifies TNFRp55 in uterine cells decreased (Roby et al. 1996). These date indicate that estradiol may modulate the expression of the gene encoding TNFRp55. Whether this mechanism is involved in the decreased susceptibility of endometriotic cells to apoptosis associated to estradiol remains to be investigated.

In conclusion, the deficiency of TNFRp55 promoted the establishment and development of endometriosis through an increase in the lesion size and high levels of estradiol, which correlate with an increase in the MMP-2 activity. Further studies on the deregulation of the TNFRp55 expression and the survival of the endometrial cells in ectopic sites might contribute to improve the knowledge about pathophysiology and discover possible therapies or biomarkers of endometriosis.

\section{Declaration of interest}

The authors declare that there is no conflict of interest that could be perceived as prejudicing the impartiality of the research reported.

\section{Funding}

This work was supported by Grant PROICO 2-1812 CyT-UNSL and Fundación Florencio Fiorini (2012-2013).

\section{Acknowledgements}

The authors gratefully thank Laboratorio de Inmunopatología (IMIBIOSL CONICET, UNSL) for providing KO mice. They also thank PhD Carlos Telleria, Co-Director Postdoctoral Scholarship-CONICET. This work is part of the Postdoctoral Scholarship-CONICET of PhD Sandra Vallcaneras and Doctoral thesis of Federica Ghersa.

\section{References}

Ahn SH, Monsanto SP, Miller C, Singh SS, Thomas R \& Tayade C 2015 Pathophysiology and immune dysfunction in endometriosis. BioMed Research International 2015 article ID 795976. (doi:10.1155/2015/795976)

Amălinei C, Căruntu ID, Giuşcă SE \& Bălan RA 2010 Matrix metalloproteinases involvement in pathologic conditions. Romanian Journal of Morphology and Embryology 51 215-228.

Antsiferova Y \& Sotnikova N 2012 The local immune mechanisms involved in the formation of endometriotic lesions. In Endometriosis: Basic Concepts and Current Research Trends, pp 211-44. Eds K Chaudhury \& BN Chakravarty. Rijeka, Croatia: Intech. (doi:10.5772/1193)

Bilotas M, Meresman G, Stella I, Sueldo C \& Barañao RI 2010 Effect of aromatase inhibitors on ectopic endometrial growth and peritoneal environment in a mouse model of endometriosis. Fertility and Sterility 93 2513-2518. (doi:10.1016/j.fertnstert.2009.08.058)

Boric MA, Torres M, Pinto C, Pino M, Hidalgo P, Gabler F, Fuentes A \& Johnson MC 2013 TNF system in eutopic endometrium from women with endometriosis. Open Journal of Obstetrics and Gynecology $\mathbf{3}$ 271-278. (doi:10.4236/ojog.2013.32051)

Bravo R \& Macdonald-Bravo H 1987 Existence of two populations of cyclin/proliferating cell nuclear antigen during the cell cycle: association with DNA replication sites. Journal of Cell Biology $\mathbf{1 0 5}$ 1549-1554. (doi:10.1083/jcb.105.4.1549)

Published by Bioscientifica Ltd. 
Bruner KL, Matrisian LM, Rodgers WH, Gorstein F \& Osteen KG 1997 Suppression of matrix metalloproteinases inhibits establishment of ectopic lesions by human endometrium in nude mice. Journal of Clinical Investigation 99 2851-2857. (doi:10.1172/ JCI119478)

Bulun SE, Zeitoun KM, Takayama K \& Sasano H 2000 Molecular basis for treating endometriosis with aromatase inhibitors. Human Reproduction Update 6 413-418. (doi:10.1093/humupd/6.5.413)

Bulun SE, Cheng YH, Yin P, Imir G, Utsunomiya H, Attar E, Innes J \& Julie Kim J 2006 Progesterone resistance in endometriosis: link to failure to metabolize estradiol. Molecular and Cellular Endocrinology 248 94-103. (doi:10.1016/j.mce.2005.11.041)

Cabal-Hierro L \& Lazo PS 2012 Signal transduction by tumor necrosis factor receptors. Cellular Signalling 24 1297-1305. (doi:10.1016/j. cellsig.2012.02.006)

Di Carlo C, Bonifacio M, Tommaselli GA, Bifulco G, Guerra G \& Nappi C 2009 Metalloproteinases, vascular endothelial growth factor, and angiopoietin 1 and 2 in eutopic and ectopic endometrium. Fertility and Sterility 91 2315-2323. (doi:10.1016/j. fertnstert.2008.03.079)

Grandi G, Mueller MD, Papadia A, Kocbek V, Bersinger NA, Petraglia F, Cagnacci A \& McKinnon B 2016 Inflammation influences steroid hormone receptors targeted by progestins in endometrial stromal cells from women with endometriosis. Journal of Reproductive Immunology 117 30-38. (doi:10.1016/j.jri.2016.06.004)

Greene AD, Lang SA, Kendziorski JA, Sroga-Rios JM, Herzog TJ \& Burns KA 2016 Endometriosis: where are we and where are we going? Reproduction 152 R63-R78. (doi:10.1530/REP-16-0052)

Grümmer R 2006 Animal models in endometriosis research. Human Reproduction Update 12 641-649. (doi:10.1093/humupd/dml026)

Haider S \& Knöfler M 2009 Human tumour necrosis factor: physiological and pathological roles in placenta and endometrium. Placenta 30 111-123. (doi:10.1016/j.placenta.2008.10.012)

Huang HF, Hong LH, Tan Y \& Sheng JZ 2004 Matrix metalloproteinase 2 is associated with changes in steroid hormones in the sera and peritoneal fluid of patients with endometriosis. Fertility and Sterility $\mathbf{8 1}$ 1235-1239. (doi:10.1016/j.fertnstert.2003.10.027)

Islimye M, Kilic S, Zulfikaroglu E, Topcu O, Zergeroglu S \& Batioglu S 2011 Regression of endometrial autografts in a rat model of endometriosis treated with etanercept. European Journal of Obstetrics and Gynecology and Reproductive Biology 159 184-189. (doi:10.1016/j. ejogrb.2011.06.029)

Jana S, Chatterjee K, Ray AK, DasMahapatra P \& Swarnakar S 2016 Regulation of matrix metalloproteinase-2 activity by COX-2-PGE2pAKT axis promotes angiogenesis in endometriosis. PLOS ONE 11 e0163540. (doi:10.1371/journal.pone.0163540)

Jiang X, Patterson NM, Ling Y, Xie J, Helferich WG \& Shapiro DJ 2008 Low concentrations of the soy phytoestrogen genistein induce proteinase inhibitor 9 and block killing of breast cancer cells by immune cells. Endocrinology 149 5366-5373. (doi:10.1210/en.2008-0857)

Kianpour M, Nematbakhsh M \& Ahmadi SM 2015 Asymmetric dimethylarginine (ADMA), nitric oxide metabolite, and estradiol levels in serum and peritoneal fluid in women with endometriosis. Iranian Journal of Nursing and Midwifery Research 20 48-49. (doi:10.4103/1735-9066.160997)

Kitawaki J, Kado N, Ishihara H, Koshiba H, Kitaoka Y \& Honjo H 2002 Endometriosis: the pathophysiology as an estrogen-dependent disease. Journal of Steroid Biochemistry Molecular Biology 83 149-155. (doi:10.1016/S0960-0760(02)00260-1)

Li Y, Adur MK, Kannan A, Davila J, Zhao Y, Nowak RA, Bagchi MK, Bagchi IC \& Li Q 2016 Progesterone alleviates endometriosis via inhibition of uterine cell proliferation, inflammation and angiogenesis in an immunocompetent mouse model. PLOS ONE 11 e0165347. (doi:10.1371/journal.pone.0165347)

Liu Y, Sun L, Hou Z, Mao Y, Cui Y \& Liu J 2016 rhTNFR: Fc suppresses the development of endometriosis in a mouse model by downregulating cell proliferation and invasiveness. Reproductive Science 23 847-857. (doi:10.1177/1933719115620495)

Othman ER, Hornung D, Hussein M, Abdelaal II, Sayed AA, Fetih AN \& Al-Hendy A 2016 Soluble tumor necrosis factor-alpha receptors in the serum of endometriosis patients. European Journal of Obstetrics and Gynecology and Reproductive Biology 200 1-5. (doi:10.1016/j. ejogrb.2016.02.025)

Pan H, Zhang P, Li JR, Wang H, Jin MF, Feng C \& Huang HF 2016 c-Fosregulated matrix metalloproteinase- 9 expression is involved in $17 \beta$-estradiol-promoted invasion of human endometrial stromal cell. Current Molecular Medicine 16 266-275. (doi:10.2174/ $1566524016666160225153454)$

Pfeffer K, Matsuyama T, Kündig TM, Wakeham A, Kishihara K, Shahinian A, Wiegmann K, Ohashi PS, Krönke M \& Mak TW 1993 Mice deficient for the $55 \mathrm{Kd}$ tumor necrosis factor receptor are resistant to endotoxic shock, yet succumb to L. monocytogenes infection. Cell 73 457-467. (doi:10.1016/0092-8674(93)90134-C)

Pitsos M \& Kanakas N 2009 The role of matrix metalloproteinases in the pathogenesis of endometriosis. Reproductive Science 16 717-726. (doi:10.1177/1933719109333661)

Quandt K, Frech K, Karas H, Wingender E \& Werner T 1995 MatInd and MatInspector: new fast and versatile tools for detection of consensus matches in nucleotide sequence data. Nucleic Acids Research 23 4878-4884. (doi:10.1093/nar/23.23.4878)

Reis FM, Petraglia F \& Taylor RN 2013 Endometriosis: hormone regulation and clinical consequences of chemotaxis and apoptosis. Human Reproduction Update 19 406-418. (doi:10.1093/humupd/ dmt010)

Rizner TL 2009 Estrogen metabolism and action in endometriosis. Molecular and Cellular Endocrinology 307 8-18. (doi:10.1016/j. mce.2009.03.022)

Roby KF, Laham N \& Hunt JS 1996 Cellular localization and steroid hormone regulation of mRNA encoding tumour necrosis factor receptor I in mouse uterus. Journal of Reproduction and Fertility 106 285-290. (doi:10.1530/jrf.0.1060285)

Rojas-Cartagena C, Appleyard CB, Santiago OI \& Flores I 2005 Experimental intestinal endometriosis is characterized by increased levels of soluble TNFRSF1B and downregulation of Tnfrsf1a and Tnfrsf1b gene expression. Biology of Reproduction 73 1211-1218. (doi:10.1095/biolreprod.105.044131)

Sampson JA 1927 Metastatic or embolic endometriosis, due to the menstrual dissemination of endometrial tissue into the venous circulation. American Journal of Pathology 3 93-110.

Vetvicka V, Laganà AS, Salmeri FM, Triolo O, Palmara VI, Vitale SG, Sofo V \& Králíčková M 2016 Regulation of apoptotic pathways during endometriosis: from the molecular basis to the future perspectives. Archives of Gynecology and Obstetrics 294 897-904. (doi:10.1007/ s00404-016-4195-6)

Received in final form 23 June 2017

Accepted 3 July 2017

Accepted Preprint published online 4 July 2017 http://joe.endocrinology-journals.org

DOI: 10.1530/JOE-17-0236
๑) 2017 Society for Endocrinology Printed in Great Britain 